\title{
Erratum: The antibiotic kasugamycin mimics mRNA nucleotides to destabilize tRNA binding and inhibit canonical translation initiation
}

Frank Schluenzen, Chie Takemoto, Daniel N Wilson, Tatsuya Kaminishi, Joerg M Harms, Kyoko Hanawa-Suetsugu, Witold Szaflarski, Masahito Kawazoe, Mikako Shirouzu, Knud H Nierhaus, Shigeyuki Yokoyama \& Paola Fucini

Nat. Struct. Mol. Biol. 13, 871-878 (2006); published online 24 September 2006; corrected after print 19 October 2006

In the version of this article initially published, the author name Mikako Shirouzo was spelled incorrectly. The correct author name is Mikako Shirouzu. This error has been corrected in the HTML and PDF versions of the article. 